\title{
研究課題別評価
}

1 研究課題名：量子縺れ最適回復プロトコル導出を可能にする量子状態の判定·測定法

2 研究者氏名:石坂 智

3 研究のねらい:

量子縺れ(量子エンタングルメント) は量子情報処理にとつて極めて重要な資源の一つである。量子通信の送信 者と受信者の様に遠く隔てられた 2 つのパーティがエンタングルメントを共有する事を考えると、初期に量子状態 が持っていたエンタングルメントの一部は伝送途中のデコヒーレンス等により破壊され、共有できるのは不完全に エンタングルした量子状態である。一方、局所操作と古典通信 (LOCC)により、この不完全にエンタングルした状 態を、元の完全にエンタングルした状態 (EPR 状態)へと回復させることができる。この回復を行うLOCC プロトコル が、エンタングルメント回復プロトコルである。このプロトコルは量子暗号通信の中継に必須であり、他の多くの量 子情報処理アプリケーションの動作効率を上げるなどの広範な応用性を持ち、極めて基本的なプロトコルである。

本研究では、エンタングルメント最適回復プロトコルの導出を将来目標に捉え、その基盤技術を拡充する為に、 量子エンタングルメントに関する数理的研究を行う。

4 研究成果:

(1) Schmidt 階数と束縛エンタングルメント

A と B、2つのパーティの系における任意のエンタングルし た純粋状態 $|\psi\rangle$ は、EPR 状態

$$
\left|\phi_{2}\right\rangle=(|00\rangle+|11\rangle) / \sqrt{2}
$$

と、確率 1 の LOCC で相互変換が可能である。しかし、この 相互変換は|$|\psi\rangle$ の同一コピー数が無限大の漸近領域に限ら

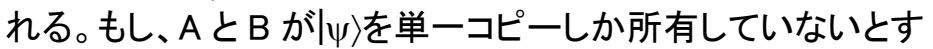
ると、LOCC による状態変換は或る強い制限を受けることに

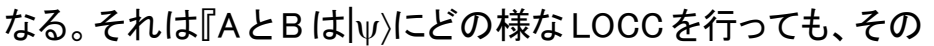
重ね合わせの項数 (Schmidt 階数、還元密度行列の階数)を 増やす事ができない』という制限である。例えば、

$$
\left|\phi_{3}\right\rangle=(|00\rangle+|11\rangle+|22\rangle) / \sqrt{2}
$$

とすると、 $\left|\phi_{2}\right\rangle \rightarrow\left|\phi_{3}\right\rangle$ の変換は確率的にすら不可能である(図 1)。また、 3 つのパーティの系における $\mathrm{GHZ}$ 状態

$$
|\mathrm{GHZ}\rangle=(|000\rangle+|111\rangle) / \sqrt{2}
$$

とW 状態

$$
|W\rangle=(|001\rangle+|010\rangle+|100\rangle) / \sqrt{3}
$$

は、 $|\mathrm{GHZ}\rangle \rightarrow|\mathrm{W}\rangle$ の変換も $|\mathrm{W}\rangle \rightarrow|\mathrm{GHZ}\rangle$ の変換も不可能であり、 $\mathrm{GHZ}$ 型と W 型は比較不可能な異なるエンタングルメントであ ると言われる(図 2)。

これらの変換を行うのに必要な最小資源は何だろうか？ この疑問に答える為に束縛エンタングルメントに着目する。 本研究により、束縛エンタングルメントは純粋状態の変換に 対して非常に強力な威力を持ち、上記 LOCC の制限を完全 に取り除いてしまう効果がある事が判明した(図 1 および図 2)。

例えば、A と B の 2 つのパーティが| $\left.\phi_{2}\right\rangle_{\text {А } 3 \text { B } 3}$ に加え、

$$
\begin{aligned}
E_{\mathrm{AB}}= & \frac{1}{7}\left|\phi_{3}\right\rangle\left\langle\left.\phi_{3}\right|_{\mathrm{A} 1 \mathrm{~B} 1} \otimes \mid \phi_{2}\right\rangle\left\langle\left.\phi_{2}\right|_{\mathrm{A} 2 \mathrm{~B} 2}\right. \\
& +\frac{1}{28}\left(I-\left|\phi_{3}\right\rangle\left\langle\phi_{3}||_{\mathrm{A} 1 \mathrm{~B} 1} \otimes\left(I-\phi_{2}\right\rangle\left\langle\phi_{2}\right|\right)_{\mathrm{A} 2 \mathrm{~B} 2}\right.
\end{aligned}
$$

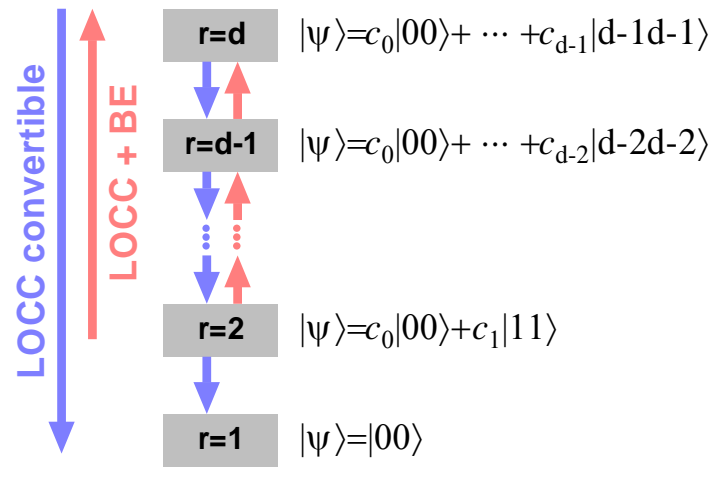

図 1. 純粋状態の LOCC 変換性と、それに対する 束縛エンタングルメント(BE)の効果。LOCC は Schmidt 階数 $(r)$ を下げる青矢印の方向にのみ 変換可能であるが、BE を利用する事により赤矢 印方向の変換が可能になる。

\section{(a) LOCC}

(b) $L O C C+B E$

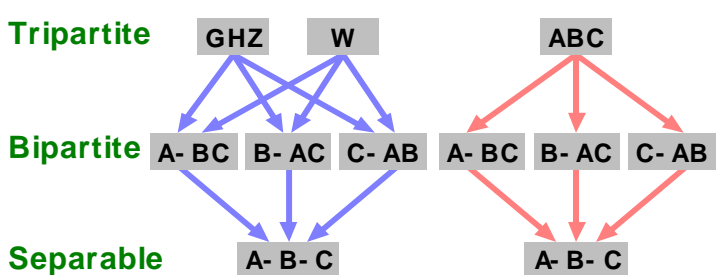

図 2.（a）LOCC と(b)束縛エンタングルメント (BE)を利用したLOCCにおける 3 量子ビットの純 粋状態の分類と変換性。

の束縛エンタングル状態を共有していたとする。もし A とB が、それぞれ A2A3 とB2B3に対しべル状態測定を行う 
と、その結果として $\left|\phi_{3}\right\rangle_{\mathrm{A} 1 \mathrm{~B} 1}$ を共有する事ができる。すなわち、 $E_{\mathrm{AB}}$ の束縛エンタングルメントを利用する事で $\left|\phi_{2}\right\rangle \rightarrow\left|\phi_{3}\right\rangle$ の変換 が可能になる。同様にして、A と B は適切な束縛エンタングル メントを利用する事で、エンタングルした純粋状態の Schmidt 階数を幾らでも増やす事ができる(図1)。

同様の効果は 3 つのパーティの系にも存在する。束縛エン タングルメントを利用すると、LOCC で比較不可能だった GHZ 状態と W 状態でさえも相互に変換する事が可能になる。この 事は、エンタングルメントの分類に対しても大きな意味を持つ。 3 量子ビットの系のエンタングルメントを LOCC で分類すると、 3 体のエンタングルメントとしては GHZ 型とW 型の 2 つが存在 するが、束縛エンタングルメントを利用した LOCC で分類を行 うと、GHZ 型と $W$ 型は同じ型に属してしまう事を意味している （図 2)。一般に、 $N$ 個のパーティの系におけるエンタングルメ ントをLOCC で分類すると、比較不可能な型が無限個存在する事になり、分類は極めて複雑になるが、束縛エンタ ングルメントを利用した LOCC で分類すると、それら異種エンタングルメントは全て同一の型に属する事になる。こ の様に、束縛エンタングルメントにはエンタングルメントの分類を著しく簡単化すると言う効果がある。

束縛エンタングルメントを利用したLOCC はPPT 保存写像の一つであり、変換における最大確率はPPT 保存写 像を考える事で定量的に議論できる。この問題は、convex optimization へと帰着させる事ができ、更に状態が持 つ対称性を利用する事で上記変換の最大確率 $(P)$ を求める事ができる。結果のみを示すと、 $\left|\phi_{\mathrm{d}}\right\rangle \rightarrow\left|\phi_{\mathrm{d}}\right\rangle \mid$ に対して は

$|\mathrm{GHZ}\rangle \rightarrow|\mathrm{W}\rangle \mid$ 対しては

$$
P=\mathrm{d}(\mathrm{d}-1) /\left(\mathrm{dd}^{\prime}+\mathrm{d}^{\prime}-2 \mathrm{~d}\right),
$$

$$
P=\frac{1}{4}\left[(18+6 \sqrt{3})^{1 / 3}+(18-6 \sqrt{3})^{1 / 3}-2\right] \approx 0.75436 \ldots
$$

である。LOCC における $|\mathrm{GHZ}\rangle \rightarrow|\mathrm{W}\rangle$ の最大変換確率がゼ口(変換不可能)である事を考えると、PPT 保存写像にお ける同変換の $75 \%$ 以上の変換確率は極めて大きなものであり、束縛エンタングルメントは定量的にも強力な威力を 持っている事が分かる。

EPR 光源を用いて束縛エンタングル状態を実験的に生成し、束縛エンタングルメントが持つ非局所性の威力を 実験的にデモンストレーションする事も可能である。先に記した $E_{\mathrm{AB}}$ を利用する $\left|\phi_{2}\right\rangle \rightarrow\left|\phi_{3}\right\rangle$ の変換に対応する実験ス キームを図 3 に示す。この実験スキームにおいて量子ゲートは必要なく、線形光学の技術で実現が可能である。

(2)多体エンタングルメントの等価性

2 つのパーティの系における任意のエンタングルした純粋状態 $|\psi\rangle$ は、 $n$ が無限大の漸近領域であれば

$$
|\psi\rangle^{\otimes_{n}} \leftrightarrow\left|\phi_{2}\right\rangle^{\otimes_{n E}}
$$

の相互変換が確率 1 の LOCC で可能である( $E$ は| $\psi\rangle$ の還元密度行列の von Neumann エントロピー)。これにより、 全ての 2 体のエンタングルメント EPR 状態のエンタングルメントと等価であるとされる。ところが、 3 つのパーティ

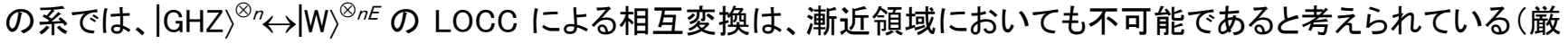
密な証明はなされてはいないかった)。

一方、単一コピーの場合、PPT 保存写像で $|\mathrm{GHZ}\rangle \leftrightarrow|\mathrm{W}\rangle$ の確率的な相互変換が可能になる事を(1)で示した。で は、PPT 保存写像は漸近領域において $|\mathrm{GHZ}\rangle^{\otimes_{n}} \leftrightarrow|\mathrm{W}\rangle^{\otimes_{n E}}$ の相互変換をも可能にするのだろうか ?これは、エンタ ングルメントの等価性に関する基本的で重要な問題であると言える。

これを明らかにする為には、幾つかのエンタングルメント測度の值を漸近領域で求めなければならない。エンタ ングルメント測度の計算は一般的に困難であり、ましてや漸近領域での計算は極めて困難である。しかしながら、 本研究では幾つかの状態クラスに対する漸近的エンタングルメント測度を計算する事に成功した。

まず、スピン 0 状態

$$
|\mathrm{A}\rangle=\frac{1}{\sqrt{6}} \sum_{i j k=1}^{3} \varepsilon_{i j k}|i j k\rangle
$$

に対する 3 体の相対エントロピー・エンタングルメント測度 $\mathrm{E}_{3}$ は

$$
\mathrm{E}_{3}\left(|\mathrm{~A}\rangle^{\otimes_{2}}\right)<2 \mathrm{E}_{3}(|\mathrm{~A}\rangle)
$$

を満たし、劣加法的である事が示せる。すなわち、一般に漸近的エンタングルメント測度は非漸近的測度の值とは 
一致しない。そこで、 $\mathrm{E}_{3}\left(\sigma_{\mathrm{ABC}}\right)$ とその漸近的測度 $\mathrm{E}_{3}^{\infty}\left(\sigma_{\mathrm{ABC}}\right) 、 2$ 体の漸近的測度 $\mathrm{E}_{2}^{\infty}\left(\sigma_{\mathrm{AB}}\right)$ 、および von Neumann エント ロピーS $\left(\sigma_{\mathrm{AB}}\right)$ の間で成立する不等式

$$
\mathrm{E}_{3}\left(\sigma_{\mathrm{ABC}}\right) \geq \mathrm{E}_{3}^{\infty}\left(\sigma_{\mathrm{ABC}}\right) \geq \mathrm{E}_{2}^{\infty}\left(\sigma_{\mathrm{AB}}\right)+\mathrm{S}\left(\sigma_{\mathrm{AB}}\right)
$$

に着目する。筆者が以前に得た 2 量子ビットにおける相対エントロピー・エンタングルメント測度の関係式を用いる と、もし 2 量子ビットの混合状態 $\sigma_{A B}$ が、その最近接のエンタングルしていない状態と可換であれば、 $E_{2}\left(\sigma_{A B}\right)$ が弱加 法的になる事を示せる。この結果と上記不等式を用いると、W 状態に対する $E_{3}(W)$ 弱加法的であり、 $E_{3}^{\infty}(W)=\log (9 / 4)$ である事が分かる。これより、GHZ 状態と W 状態に対する還元 von Neumann エントロピーは

$$
\mathrm{S}_{\mathrm{A}}(\mathrm{GHZ})=1>0.92=\mathrm{S}_{\mathrm{A}}(\mathrm{W})
$$

の不等式を満たし、 $E_{3}^{\infty}$ は

$$
\mathrm{E}_{3}^{\infty}(\mathrm{GHZ})=1<\log (9 / 4)=\mathrm{E}_{3}^{\infty}(\mathrm{W})
$$

の不等式を満たす。もし、確率 1 の PPT 保存写像で $|G H Z\rangle^{\otimes_{n}} \leftrightarrow|\mathrm{W}\rangle^{\otimes_{n} E}$ の相互変換が可能であるとすると、全ての連 続な漸近的エンタングルメント測度 $R^{\infty}$ に対し

$$
\mathrm{R}^{\infty}(\mathrm{GHZ})=\alpha \cdot \mathrm{R}^{\infty}(\mathrm{W})
$$

が成立する様な係数 $\alpha$ 存在しなければならない。しかし、上記の $\mathrm{S}_{\mathrm{A}}$ と $\mathrm{E}_{3}^{\infty}$ の不等式により、その様な $\alpha$ は存在し 得ず、GHZ 型とW 型のエンタングルメントは、PPT 保存写像においても等価にはなり得ないと結論できる。

同様にして、GHZ 型のエンタングルメントは、W 型と $A B 、 A C 、 B C$ 間の EPR 型のエンタングルメントには分割不 可能であるとの結論も得られる。LOCC は PPT 保存写像に含まれるので、これらの結論は LOCC でも成立する。

（3）強い単調性とエンタングルメント回復

先に述べた状態変換における制限、『どの様な LOCC も、 純粋状態の Schmidt 階数を確率的にすら増やす事ができな い』は、強い単調性の一つである。これを混合状態に拡張し た強い単調関数は Schmidt 数と言われる。一方、PPT 保存 写像は、これらの強い単調性を取り除いてしてしまう事を(1) で示した。これにより、エンタングルした純粋状態は全て確率 的に相互変換可能になった。これは、純粋状態の変換に関 する強い単調性が Schmidt 数しか存在しないからである。で は、混合状態に関する変換では、どうなるのだろうか?この 問題は単一コピーにおけるエンタングルメント回復と深く関係 した重要な問題である。

混合状態から EPR 状態への恋換(すなわち単一コピーの エンタングルメント回復)

$$
\sigma \rightarrow\left|\phi_{2}\right\rangle
$$

を考える。 $\sigma を C^{d} \otimes C^{d}$ 上の混合状態とすると、 $\sigma$ の階数が

$$
\operatorname{rank}(\sigma) \geq d^{2}-2
$$

と高い場合、PPT 保存写像の下でも単一コピーのエンタング ルメント回復が不可能である事を本研究で証明した。先に述 ベた通り、PPT 保存写像は Schmidt 数の強い単調性を取り 除いてしまう。よって、上記の結論は、混合状態の変換にお いては、PPT 保存写像でも取り除けない強い単調性が残っ ている事、すなわち Schmidt 数と独立な強い単調性が存在し ている事を意味している。

そこで、本研究では幾何学的なアプローチにより、Schmidt 数とは独立な強い単調関数の導出も行った。まず、正行列 の集合を考える。密度行列 ( $\sigma$ )は(規格化条件を除いて)正 行列 $(\sigma \geq 0)$ なので、正行列の集合は密度行列の集合に相 当する。また、PPT 行列の集合を考える。PPT 行列とは、部 分転置をすると正行列になる行列である。これら 2 つの集合 の模式図を図 4 に示した。2 つの集合の共通部分は PPT 状 態、すなわち Peres criterionを満たす状態で、典型的にはエ ンタングルしていない状態である(束縛エンタングル状態も一 部含まれる)。

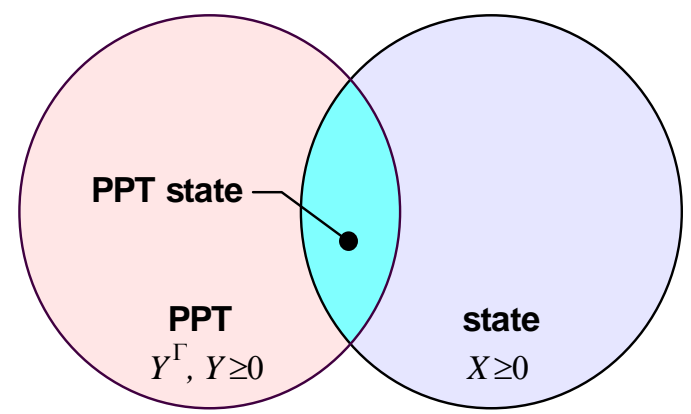

図 4. 密度行列(正行列)の集合とPPT 行列の集 合の幾何学的模式図。共通部分はPeres criterion を満たす状態(PPT 状態)。

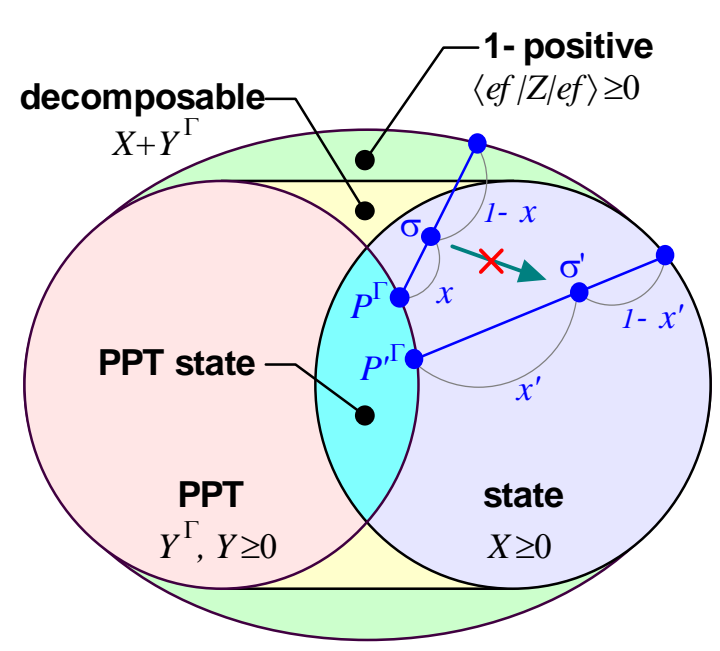

図 5. エルミ一ト行列の集合の幾何学的模式図。 密度行列と PPT 行列の集合は decomposable 行 列と 1-positive 行列の集合の一部である。密度 行列のを図の様に凸結合で表現した時の最小内 分比 $\mathrm{x}$ は強い単調関数となる。 
まず、この幾何学的構造に着目する事で、エンタングルメント理論における重要な未解決問題の一つ、 binegativity problem を解決する事に成功した。すなわち、全ての 2 量子ビットの密度行列が、

$\left|\sigma^{\Gamma}\right|^{\Gamma} \geq 0$

を満たす事を厳密に証明した。

また、正行列と PPT 行列の凸結合で記述できる行列は decomposable 行列、直積状態による期待值が常に正 ( $\langle e f|X| e f\rangle \geq 0)$ となる行列は 1-positive 行列と呼ばれる。全ての decomposable 行列は 1-positive 行列であるの で、エルミ一ト行列の集合は、図 5 の様な構造をしていると考えられる。

この幾何学的構造に着目し、混合状態の密度行列のをPPT 行列と 1-positive 行列の凸結合で表現する事を考 える。その際、 $\sigma$ 「の Jordan 分解 (直交分解)を

$$
\sigma^{\Gamma}=P-Q
$$

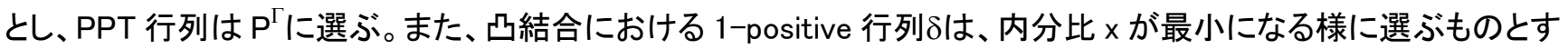
る(図 5)。この最小の内分比 $\mathrm{x}$ は、混合状態における強い単調関数の一つであり、LOCCでは確率的にすら増やす

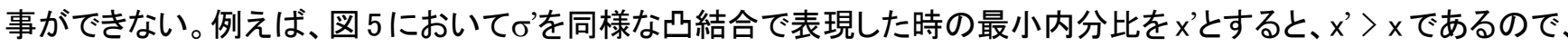
$\sigma \rightarrow \sigma^{\prime}$ の LOCC 変換は確率的にすら不可能であると結論できる。密度行列 $\sigma を \mathrm{P}^{\Gamma}$ と decomposable 行列の凸結合 で表現した場合でも、その最小内分比は別の強い単調関数の一つとなる。大雑把に言うと、混合状態の LOCC 恋 換は、PPT 状態へと近づく方向へしか許されていない事になる。

これら最小内分比[以下 $\mathrm{M}_{1}(\sigma)$ とする]が強い単調関数の一つである事は、convex optimization における双対性 を用いて証明する事ができる。また $M_{1}(\sigma)$ は、全てのエンタングルしていない状態に対して 0 の值を取り、全てのエ ンタングルした純粋状態に対して 1 の值を取る。エンタングルメント回復とは、混合状態をエンタングルした純粋状 態、すなわち $M_{1}=1$ の状態へと変換する事である。 $M_{1}$ は LOCC で確率的にすら増やせないので、これより直ちに、 エンタングルメント回復できる混合状態 $\sigma$ は $M_{1}(\sigma)=1$ を満たさなければならない事が分かる。また、これらの状態は、 1-positive 行列の集合の境界に位置しなければならない事も図 5 より直ちに分かる。これらは、単一コピーにおけ るエンタングルメント回復が可能である為の必要条件である。なお、コピー数が $n$ の状態のエンタングルメント回復 は、 $\rho=\sigma^{\otimes_{n}}$ の単一コピーのエンタングルメント回復と捉える事ができるので、ここで導出した必要条件は、コピ一数 が有限である場合のエンタングルメント回復全てに適用される。

5 自己評価:

状態空間の幾何学的構造の解析を通して量子エンタングルメントの基礎的性質を明らかにし、状態空間の幾 何学的構造と量子情報処理の間の関係を解明する事が当初の研究計画であった。しかし、研究開始直後に束縛 エンタングルメントの全く新しい性質を思いがけず発見した。この性質は、(1)パーティの数や系の次元に関係なく 広〈現れる一般的なものであり、(2)量子エンタングルメントの分類という基本的な事柄とも密接に関係しているも のであった。そこで、これは重要な性質であると判断し、定量的解析や漸近領域における振舞い等の詳細な研究 を行った。量子情報における理論研究の様な基礎研究では、必ずしも計画通りに研究が進む訳ではないので止 むを得ない事だし、柔軟に対応する事が重要だと思っているが、当初の研究計画とは異なってしまったことは確か である。

しかし、混合状態の場合におけるこの性質の意味を落ち着いて考えて見ると、この性質は強い単調性を通して 単一コピーのエンタングルメント回復と関係があることに気づいた。そこで、当初の研究計画に戻り、状態空間の 幾何学的性質に着目し、新しい強い単調性の導出および単一コピーのエンタングルメント回復の必要条件の導出 を行った。これにより、エンタングルメント回復と状態空間の幾何学的性質の関係の一つの側面を明らかにするこ とができた。この研究は研究計画に沿ったものではあったが、成果のインパクトや応用上の重要性(特に導出した 強い単調関数の計算可能性)に関しては問題があったと思う。

また、この 3 年の短い研究期間の間で、量子情報の研究に対する学会や企業の姿勢が大きく変化したと感じた。 以前にも増して、量子情報の新しい方向性や新しい応用先を必要としている様に思う。特に新しい応用先の発掘 に関しては、企業のマネージメントサイドからも強く要望されているところである。この情勢の変化を踏まえ、最終 年度の後半では、研究総括の許可を得て現代暗号量子プロトコルの研究に着手した。この研究に関しては、残念 ながら期間中に成果を上げることはできなかったが、次のステップへの重要な足がかりを得ることができた期間に なったと思う。

6 研究総括の見解:

研究の進展の中で発見した束縛エンタングルメントの性質に関して重要な研究成果を上げました。それが、計 画の本筋に関係の深い強単調性に結びついた点について、見事な研究展開と評価します。

5 編の論文のうち 3 編は単著であり、残りの 2 編も石坂智研究者の貢献が大であることは、石坂智研究者の力 
量をあらわしています。この分野に大きく貢献しましたので、この人を研究者として採択したことは成功であったと 思っています。

\section{7 主な論文等:}

論文: 6 件

[1] S. Ishizaka, "Binegativity and geometry of entangled states in two qubits", Phys. Rev. A 69, 020301-1 020301-4 (Rapid communication) (2004)

[2] S. Ishizaka, "Bound entanglement provides convertibility of pure entangled states", Phys. Rev. Lett. 93, 190501-1 - 190501-4 (2004)

[3] S. Ishizaka and M. B. Plenio, "Multiparticle entanglement manipulation under positive partial transpose preserving operations", Phys. Rev. A 71, 052303-1 - 052303-13 (2005)

[4] S. Ishizaka and M. B. Plenio, "Multiparticle entanglement under asymptotic positive partial transpose preserving operations", Phys. Rev. A 72, 042325-1 - 042325-5 (2005)

[5] S. Ishizaka, "Strong monotonicity in mixed-state entanglement manipulation", Phys. Rev. A 73, 062308-1 062308-6 (2006)

特許：0 件

受賞：0 件

招待講演：0 件

その他

解説: 2 件

[1] 石坂智、「束縛エンタングルメント」、数理科学、2005 年 2 月号

[2] 石坂智、「EPR パラドックス」、月刊オプトロニクス、2007 年 3 月号

チュートリアル講演·講師・レビュ一講演： 3 件

[1] 石坂智、「混合状態のエンタングルメント」、第 11 回量子情報技術研究会

[2] 石坂智、「二者間および多者間エンタングルメントとその周辺」、第 14 回非平衡系の統計物理シンポジウム

[3] S. Ishizaka, "Theory of entanglement for mixed states", The 6th Workshop on Fundamental Problems and Applications of Quantum Field Theory

国内学会発表：6 件

国際学会発表: 4 件

[1] S. Ishizaka, "Effect of bound entangled states on the convertibility of pure entangled states", The 7-th International Conference on Quantum Communication, Measurement and Computing 2004

[2] S. Ishizaka, "Binegativity and geometry of entangled states in two qubits", ERATO conference on Quantum Information Science 2004

[3] S. Ishizaka, "Bound entanglement and convertibility of pure states", ERATO conference on Quantum Information Science 2004

[4] S. Ishizaka, "Strong monotonicity in mixed-state entanglement manipulation", Asian Conference on Quantum Information Science 2006 